\title{
Panel seeks 'fundamental' shift in handling of observation data
}

[WASHINGTON] The US Mission to Planet Earth (MTPE), which includes a multibillion-dollar series of satellites to observe the planet, oceans and atmosphere, is undergoing yet another major review that may complete the programme's evolution from the use of large, centralized spacecraft to a smaller and more distributed system.

One early result of the review is "an absolutely fundamental change in philosophy" as to how data from the Earth Observing System (EOS) of satellites are disseminated, according to Steven Wofsy, an environmental scientist at Harvard University and the new chair of NASA's advisory group for Earth science.

Since it began in 1991, the MTPE has been revised on many occasions, its spacecraft have shrunk in size, and its projected budget has dropped from $\$ 18$ billion to just over $\$ 6$ billion. But the current issue is not money. NASA is revamping the programme at a time when the budget appears stable and the first launch - of the AM-1 spacecraft is only a year away.

Michael Mann, the agency's deputy administrator for Earth science, says the purpose of this first 'biennial review' is to develop a strategy for the mission "that allows us to be flexible" and to respond to criticisms and recommendations from outside groups.

The latest - and probably bluntest such criticism came recently from Wofsy's panel, which is part of the NASA Advisory Council. In a letter sent last week to Daniel Goldin, NASA administrator, the council made three pointed recommendations.

First, it said there should be a "fundamental change" to the EOS Data and Information System (EOSDIS) designed to

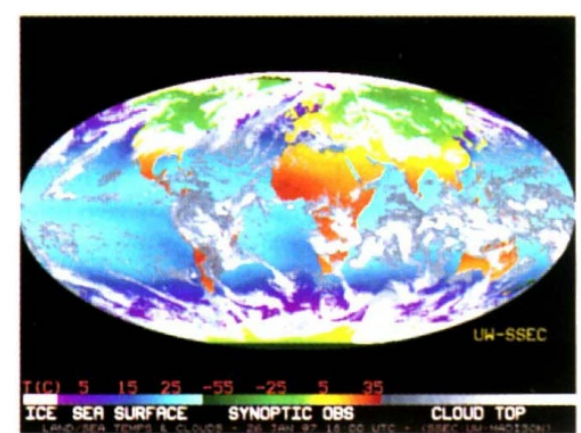

Global vision: satellite data such as that in this temperature map have become invaluable

process, archive and distribute data from dozens of orbiting instruments. "The requirements should be limited and realistic, the architecture should be open, and the data products should be largely the responsibility of the principal investigators."

The EOSDIS is behind schedule and has suffered technical problems, most recently when it failed a major integration test early this year. The data system, which before the current review was projected to cost as much as $\$ 2$ billion, has been singled out for reform by other review panels. They have advised NASA to move away from large, centralized databanks to a "federation" of smaller data providers (see Nature 377, 191; 1995).

NASA is committed to having some kind of EOSDIS in place for the AM- 1 and Landsat 7 missions, says Mann. But it has suspended work on subsequent versions. The EOSDIS could even be scrapped altogether, with scientists simply releasing processed data from individual instruments over the Internet.

Wofsy's panel argues that whatever system takes its place should serve scientists

\section{Senate bill seeks controls on genetic data}

[WASHINGTON] A far-reaching bill that would bar employers and insurers from discriminating on the basis of genetic information was introduced into the US Senate last week by Pete Domenici (Republican, New Mexico).

The bill has been welcomed by consumer and privacy advocates. But it is opposed by many researchers, who argue that it would impose new responsibilities and procedures on them. Francis Collins, director of the National Human Genome Research Institute, called the bill impracticable.

The Genetic Confidentiality and Nondiscrimination Act of 1997 would also require any third party to obtain a donor's informed and written consent to "collect, store, analyze or disclose an individual's genetic information". The bill's wording has been slightly revised from a 1996 version; for example, a provision establishing an individual's ownership of his or her DNA has been deleted.

But some researchers say that the bill would still cripple research by drastically reducing access to tissue samples from the country's vast library of stored pathological specimens. The bill is "unacceptably restrictive and burdensome," says one.

The bill has been referred to the Senate Labor and Human Resources Committee, whose chairman, James Jeffords (Republican, Vermont), is one of the bill's co-sponsors.

Meredith Wadman first. "Those components [of the current system] that do not meet limited requirements for defined scientific and applications users should be cancelled or modified." Critics say one of the problems with the current EOSDIS is that it has been asked to serve too many masters, from scientists to schoolchildren to the general public. Mann says non-scientist "customers" might still be provided for, depending partly on the cost.

The advisory council also recommends - and NASA has tacitly agreed - that all EOS missions after PM-1 in 2000 (for which hardware is already being built) should be "completely re-examined" to favour smaller, faster missions that can take advantage of new technology and new scientific thinking.

The programme may even set a new competition to provide the instruments to be flown on CHEM-1, the next spacecraft in the series, even though some investigators have been working on the project for nearly a decade. Wofsy says the MTPE will benefit from continually re-evaluating the scientific questions it asks, and from being able to fly a greater number of "hypothesis-driven missions" with shorter turn-around times. One model for this approach is the new low-budget Earth System Science Pathfinder series of missions, the first two of which were to be selected this week.

Finally, says the panel, next year the MTPE programme should shift from its heavy emphasis on spacecraft observations to "substantially increase the resources devoted to in-situ and process studies, modelling and analysis". In other words, less money should be spent on orbiting hardware, and more on ground- and aircraftbased research.

Yet to be decided is how all these reforms will affect one of the EOS system's original goals, namely to gather the same key measurements from the same set of instruments flying in space over many years, in part to avoid calibration problems that make it difficult to work out long-term trends.

Some supporters of the MTPE worry that such a sweeping re-evaluation of the programme as it approaches its first launch signals confusion and a lack of clear goals. Others applaud the new flexibility as a sign of progress, aliberation from NASA's old practice of locking in technologies and scientific strategies years ahead of a launch, which bars new ideas.

That debate is certain to be taken up in Congress this year. Hearings on the Mission to Planet Earth were due to be held before the House Science Committee's subcommittee on space this week.

Tony Reichhardt 